\title{
Transformações dos sistemas de saúde na era da financeirização. Lições da França e do Brasil
}

\author{
The reshaping of healthcare systems in the age of financialization. \\ Lessons from France and Brazil
}

Ana Carolina Cordilha ${ }^{1}$

Lena Lavinas ${ }^{2}$
${ }^{1}$ Universite Paris 13.99 Av. Jean Baptiste Clement, Campus de Villetaneuse. 93430 Villetaneuse Paris França. carolinacordilha@ hotmail.com

${ }^{2}$ Instituto de Economia, Universidade Federal do Rio de Janeiro. Rio de Janeiro RJ Brasil.

\begin{abstract}
Since the post-War period, social protection systems have experienced continuous reforms, either extending or, more often, reducing the scope and the scale of public provision. This paper seeks to present how healthcare systems have evolved both in France and in Brazil recent$l y$, in order to comprehend mechanisms through which financialization has been reshaping public care provision. This comparative analysis unveils distinct financialization dynamics of healthcare systems, built upon universalism principles. After featuring both systems, underlying their private dimension - either complementary or supplementary - the article points out how the financial sector is broadening its share in the supply of healthcare services. In what follows, the sector's process of internationalization/centralization is analyzed and lastly the regulatory role of the State in strengthening private provision is defined. Despite radically different institutional paths, the findings corroborate that in both cases finance is a driving force in reshaping the healthcare sector. Key words France, Brazil, Financialization, Complementary Healthcare Provision, Supplementary Healthcare Provision
\end{abstract}

Resumo Desde a segunda metade do século XX, reformas tornaram-se contínuas no âmbito dos sistemas de proteção social, ampliando ou, com mais frequência, restringindo o escopo e a escala da provisão pública. Neste artigo, cotejamos a evolução recente dos sistemas de saúde na França e no Brasil, de modo a apreender os mecanismos através dos quais a "financeirização" vem reformatando a provisão pública. Essa abordagem comparada tem por finalidade explicitar dinâmicas diferenciadas de penetração do capital financeiro em sistemas de saúde que se pautaram por princípios universalistas. Após caracterizar brevemente ambos os sistemas de saúde, destacando o alcance da provisão privada seja complementar, seja suplementar, o artigo mostra como o setor financeiro vem ampliando sua participação na oferta de serviços de saúde. Em seguida, analisa como se dá o processo de internacionalização/centralização do setor, e, finalmente, sintetiza o papel regulatório do Estado no fortalecimento da provisão privada. Os resultados indicam que, a despeito de trajetórias institucionais radicalmente opostas, a marcha da financeirização avança no setor de saúde.

Palavras-chave França, Brasil, Financeirização, Saúde complementar, Saúde suplementar 


\section{Introdução}

A crise dos sistemas públicos de saúde é tema recorrente não apenas entre especialistas e acadêmicos, mas também - e sobretudo - nas manchetes da grande imprensa em todas as latitudes. De um lado, é manifesto o subfinanciamento derivado da adoção de políticas de austeridade nos países desenvolvidos onde o gasto com saúde é eminentemente público - caso do Reino Unido e da França, por exemplo. De outro, são crescentes os custos em consequência do aumento da longevidade associada aos processos de inovação no setor que tornam a assistência médica mais dispendiosa a cada dia. O rebatimento mais imediato é o fortalecimento progressivo da oferta privada de serviços de saúde, cuja expansão tem lugar de forma altamente segmentada, variando de acordo com o nível de renda dos indivíduos e famílias, o que por si só indica uma acessibilidade potencialmente mais limitada.

Dentre as muitas explicações que buscam apreender as mudanças em curso e os desafios que se colocam para os sistemas de saúde, cujas reformas tornaram-se constantes e incontornáveis, qualquer que seja a marca ideológica deste ou daquele governo, uma delas ganha relevância: a dominância do capitalismo financeirizado ${ }^{1-3}$. Entendido como novo regime de acumulação da era neoliberal, o capitalismo financeirizado parece comprometer em definitivo modelos de provisão pública que, surgidos no imediato póssegunda guerra, pretendiam-se universais, gratuitos e integrais.

Ora, universalidade, gratuidade e integralidade são os alicerces do sistema único de saúde (SUS) brasileiro, desde sua criação em 1988, à imagem no National Health System (NHS) britânico. Lastreiam, outrossim, os princípios norteadores do alargamento e altíssima cobertura do seguro saúde na França e em outros países europeus, onde sistemas de proteção social consolidaram-se paulatinamente na segunda metade do século XX, fazendo do direito à saúde um marco da cidadania e um diferencial de monta na luta contra as desigualdades.

Contudo, a ascendência da financeirização ao subsumir também a esfera da reprodução social ${ }^{4}$ coloca em xeque seguranças que ganhavam raízes.

No campo da saúde, as facetas visíveis da financeirização materializam-se de diversas formas. Como aponta Bayliss ${ }^{5}$, uma dimensão ocorre, "em parte, através da privatização, com parcela crescente dos serviços de saúde sendo contratada junto a investidores privados (...), sendo que os provedores privados são apoiados por instituições financeiras". Da mesma forma, a existência de déficits no ramo hospitalar abre uma avenida de investimentos para o capital privado, que, ademais, serve-se do argumento da eficiência, para justificar o aumento gradual e persistente de sua penetração. Assim, resume Bayliss, "a provisão de serviços de saúde tem-se transformado num ativo financeiro que integra o portfolio de investimentos globais de interesse de investidores privados", notadamente fundos de private equity ${ }^{5}$.

Neste artigo, vamos analisar dois países com sistemas de saúde públicos e universais, a França e o Brasil, com vistas a identificar, a partir das reformas recentes, os mecanismos através dos quais o processo de financeirização vem reconfigurando o acesso e as formas de provisão deste setor.

Assim, a segunda seção, na sequência desta introdução, faz uma breve caracterização dos sistemas de saúde brasileiro e francês, traçando sua engenharia institucional e as modalidades de articulação entre o público e o privado, grau de cobertura e escopo de atendimento, além das formas de financiamento. Ambos os países adotaram um modelo financiado por impostos e contribuições, embora com diferenças significativas. Ambos, cada um à sua maneira, sofrem mudanças estruturais por força da dominância financeira.

Na terceira seção, a meta é revelar como se dá a penetração da lógica financeira em ambos os sistemas, enfatizando mudanças no comportamento dos provedores; dinâmicas de fusão e aquisição no setor; e regulação estatal. Na França, a financeirização avança pela transformação da saúde complementar, responsável ainda hoje por tão somente $13,3 \%$ das despesas com serviços médicos ${ }^{6}$. Ela se torna não apenas obrigatória (a partir de 2016) para todos os assalariados, bem como passa a oferecer níveis crescentes e mais onerosos de cobertura, denominadas sobrecomplementar, perdendo paulatinamente sua dimensão não lucrativa (mutualista). No caso brasileiro, tal progressão se dá de maneira radicalmente distinta, com a medicina privada, já predominante (57\% do gasto com saúde é privado), consolidando-se com o aval do Estado, através de incentivos e desonerações em favor das grandes seguradoras e fundos de pensão internacionais que fazem da saúde plataforma de investimento e altos retornos financeiros?

$\mathrm{Na}$ quarta parte, esboçamos brevemente algumas conclusões. 


\section{Os sistemas de saúde na França e no Brasil}

A caracterização inicial dos sistemas de saúde na França e no Brasil, ao evidenciar as particularidades da ação do Estado e da participação do setor privado na sua interface com a provisão pública, permite identificar trajetórias institucionais distintas.

\section{Institucionalidade, organização e princípios fundamentais}

Em ambos os países, os sistemas públicos de saúde (Assurance Maladie ou AM e Sistema Único de Saúde, respectivamente) integram regimes mais abrangentes de Seguridade Social, estabelecidos para garantir o acesso a direitos considerados fundamentais por toda a população, tais como saúde, previdência, assistência e direitos do trabalho. Instituídos sob princípios de equidade na cobertura e solidariedade no financiamento, estes sistemas revolucionaram a lógica da proteção social existente até então. Na Saúde, esta apoiava-se na filantropia e em esquemas de seguros individuais, contributivos, restritos a somente uma parte da população (sobretudo trabalhadores e seus dependentes). A despeito destas semelhanças, esses sistemas apresentam trajetórias diferentes de consolidação e articulação com o setor privado.

Na França, a Seguridade Social, criada em 1945 e institucionalizada na Constituição de 1946, acompanhou a onda de criação dos Estados de Bem-Estar em diversos países da Europa no pós-Segunda Guerra. Os serviços de atenção à saúde asseguram a cobertura de despesas e provisão de cuidados, baseados em três princípios fundamentais: igualdade de acesso, qualidade dos cuidados e solidariedade. A Assurance Maladie manteve a lógica dos seguros, que passou, contudo, a atuar de forma "residual" à provisão pública, preservando grande parte da elevada fragmentação e autonomia original das instituições que ofereciam assistência de saúde numa ótica corporativa.

A AM cobre parcial ou totalmente os custos de uma ampla gama de serviços de saúde providos pelo setor público ou por agentes privados, exonerando ou reembolsando seus custos de acordo com a natureza do bem ou serviço, da situação financeira e da condição de saúde do indivíduo. Via de regra, a parcela dos custos assumida pelo setor público gira em torno de $70 \%$ do preço de referência estabelecido pela $A M$ para consultas médicas e exames laboratoriais, $80 \%$ para hospitalização, $60 \%$ para serviços como óptica e ortopedia e até $100 \%$ para medicamentos. Após o reembolso pela $A M$, os restos a pagar podem ser total ou parcialmente reembolsados por contratos de seguro complementar (complémentaires santé), ou via desembolso direto. Recorde-se que esse sistema complementar institui-se e ganha densidade através das entidades mutualistas, sem fins lucrativos, vinculadas a categorias sócio-ocupacionais.

Descentralizado do ponto de vista local e institucional, o sistema de Seguridade francês divide-se em três regimes principais [(i) Regime Geral; ii) dos trabalhadores agrícolas; iii) independentes], cada qual com "caixas" próprias de financiamento, divididas em instâncias nacionais e locais.

$\mathrm{Na}$ atualidade, três dispositivos importantes contemplam a integralidade da cobertura médica: i) a Couverture Maladie Universelle de Base (1999)/agora denominada Protection Universelle Maladie - PUMA (2016); ii) a Couverture Maladie Universelle Complémentaire - CMU-C (1999); iii) a Aide à l'Acquisition d'une Complémentaire Santé - ACS (2004).

A primeira (PUMA), destina-se aos residentes legais que não estão inicialmente afiliados a nenhum dos regimes existentes, garantindo o reembolso proporcional das despesas, tal como previsto no âmbito da Seguridade Social. Para aqueles que não podem arcar com os restos a pagar após o reembolso da parcela de responsabilidade do Estado, a $C M U-C$ viabiliza a afiliação gratuita a um organismo de seguro complementar para indivíduos com renda inferior a um certo patamar (patamar esse variável, segundo condição familiar e lugar de domicílio). Já a ACS estabelece um desconto do prêmio de seguro complementar para aqueles com rendimentos até 35\% acima do teto da $C M U-C$. Esta e aquela oferecem um seguro parcial ou integralmente desonerado, pois assumido pelo Estado. Finalmente, há também a Aide Médicale de l'État - AME (1999), que assume os custos dos serviços de saúde de imigrantes em situação irregular no país.

Uma peculiaridade da $A M$ é cobrir a totalidade das despesas relativas a tratamentos de doenças permanentes e/ou de longo prazo. Ambas são totalmente financiadas pela esfera pública, livre da exigência de copagamento, qualquer que seja a renda familiar.

Diferente do caso francês, o Brasil implementou seu Sistema de Seguridade Social bem mais tarde, com a Constituição de 1988, em meio a um processo de redemocratização e na contramão 
das políticas neoliberais que já se alastravam pela América Latina.

A criação do Sistema Único de Saúde (SUS), formalizada em 1990, instituiu os princípios de universalidade, equidade e integralidade - significa dizer, o acesso por qualquer cidadão, de forma indiscriminada, a uma ampla gama de serviços cobrindo todas as dimensões da saúde (prevenção, cura e reabilitação). Cabe ao Estado prover serviços e produtos diretamente ou através da contratação de atores privados, porém de forma totalmente gratuita. Extensivo a mais de 200 milhões de pessoas, poderia ser considerado o maior sistema de saúde universal do mundo, caso funcionasse em conformidade com seus princípios. A instauração de um sistema de tal monta representou uma ruptura radical com o esquema vigente até então, de baixa institucionalidade e baseado em provedores e seguradores filantrópicos ou privados e for-profit, cujo acesso era restrito a certos grupos. Apesar do monopólio do Estado, a administração, a provisão e o financiamento do SUS são altamente descentralizados, de responsabilidade partilhada entre a União e as esferas subnacionais - incluindo 26 estados e os mais de 5.500 municípios do país.

\section{Financiamento}

Em ambos os países, a Seguridade Social conta com orçamento separado e fontes de receitas exclusivas para seu financiamento, sobretudo contribuições sociais incidentes sobre rendas do trabalho e produção. Ao longo do tempo, com a expansão da cobertura, da oferta e dos custos dos serviços, houve esforços de majoração e diversificação das fontes de recursos, além do estabelecimento de metas de gastos na área da saúde. Paradoxalmente, com necessidades crescentes de financiamento, multiplicaram-se também os mecanismos de desfinanciamento da Seguridade, mormente desonerações tributárias para o setor privado, que implicam a renúncia de montantes vultuosos de contribuições sociais. E isso acontece nos dois países.

$\mathrm{Na}$ França, as principais receitas da Assurance Maladie vêm das contribuições de empregados/ trabalhadores em geral e empregadores que incidem sobre a renda do trabalho, além de contribuições sociais incidentes sobre uma variada gama de rendas de atividades, de aposentadorias e de capital (incluindo rendas imobiliárias e dividendos). Há ainda outras taxas e contribuições que desempenham papel menor, tais como impostos sobre valor adicionado. $\mathrm{O}$ financiamento da universalização do sistema deriva em grande medida da tributação das instituições de seguro complementar, sujeitas ao chamado "imposto de solidariedade".

A $A M$ responde pela maior parte do chamado "déficit" da Seguridade, que totalizou $€-4,8$ bilhões em 2016. No mesmo ano, as desonerações do setor somaram $€ 14$ bilhões, sendo apenas parcialmente compensadas pelo Estado 8 .

Para controlar a tendência de aumento dos gastos da $A M$, o governo fixa metas anuais de seu crescimento, atualmente em torno de $2 \%$, sem caráter proibitivo caso extrapolem.

No Brasil, as receitas da Seguridade provêm principalmente de contribuições sobre salários (rendimentos do trabalho em geral) e da produção (lucro/faturamento). No entanto, a Seguridade e a saúde em particular sofrem importante desfinanciamento, destacando-se a "Desvinculação de Receitas da União" (que permite desvincular até 30\% das receitas de contribuições sociais para fins diversos do Orçamento Fiscal), além das desonerações tributárias sobre contribuições sociais, estimadas em $\mathrm{R} \$ 143$ bilhões só em $2016^{9}$. O peso do setor de saúde no âmbito do orçamento da Seguridade é marginal, até porque a maior parte do financiamento vem das esferas subnacionais (estados e municípios). Em 2016, o saldo final de saúde e assistência, juntos, foi negativo em - R\$ 24,2 bilhões, contra - $\mathrm{R} \$ 240$ bilhões no resultado tota ${ }^{10}$. Com vistas a garantir o aporte necessário de recursos para o setor, há regras para transferências de recursos entre entes governamentais e aplicação mínima de receitas pela União, estados e municípios. No entanto, estas sofreram um importante revés em 2016, frente à aprovação de novo regime fiscal para a União, com virtual congelamento dos gastos públicos por 20 anos.

\section{Modelos de articulação e subsídios ao setor privado}

No caso francês, tem-se um modelo "complementar" de articulação entre os setores público e privado, que designa a existência de seguros responsáveis por cobrir, total ou parcialmente, os custos residuais não reembolsados pelo seguro público ${ }^{11}$. Os contratos complementares, fortemente regulados, atingem $95 \%$ da população, podendo ser de natureza coletiva (geralmente obtidos como condição de trabalho) ou individual (adquiridos voluntariamente, e variáveis de acordo com o grau de risco).

Para aqueles que podem pagar por cobertura ainda mais plena, existe também a possibilidade 
de adquirir um plano "sobrecomplementar", que estende ainda mais o escopo de serviços e/ou o percentual de reembolso, mas cuja participação é residual se cotejada ao ramo complementar.

O segmento de "organizações complementares de saúde" é composto majoritariamente por instituições sem fins lucrativos - fundos mútuos ou mutualidades (com 60,5\% do total de segurados) e institutos de previdência (com 18\%). Observa-se, entretanto, o crescimento da participação de instituições com fins lucrativos, representadas pelas companhias de seguros (com $21,5 \%$ da cobertura). Cerca de $10 \%$ da população é beneficiária dos mecanismos de universalização dos seguros complementares, a saber CMU-C e ACS $^{12,13}$.

O Brasil, por sua vez, pratica um modelo "duplicado" ${ }^{11}$. Essa definição caracteriza um sistema onde os segmentos público e privado cobrem os mesmos tipos de serviços, indistintamente, com a comercialização, por parte do setor privado, de vantagens adicionais (como escape de filas e listas de espera e maior liberdade de escolha de médicos e instalações), mas sem isentar os indivíduos da contribuição para o sistema público. É, portanto, um sistema de duas mãos. O segmento de saúde privado brasileiro, altamente lucrativo, é conhecido como "Saúde Suplementar". Essa rede agrega instituições com e sem fins lucrativos (via de regra, cooperativas médicas, instituições de autogestão e filantropia, no primeiro caso, e planos de medicina de grupo e seguradoras privados, no segundo) e cobre cerca de $25 \%$ da população, concentradas principalmente em cooperativas (com $37 \%$ do total de beneficiários) e operadoras de "medicinas de grupo" ( com 38\%) $)^{14}$.

A aquisição de seguros privados de saúde por indivíduos pode ser subsidiada pelo Estado de diferentes formas. Na França, praticam-se incentivos tributários "seletivos" específicos (de baixa renda) para a aquisição de seguros complementares. A princípio, seu impacto em termos redistributivos pode ser considerado positivo, já que reduzem diferenças de acesso em relação aos mais ricos. No Brasil, por sua vez, há um grande peso de incentivos tributários "generalizados" mente indiscriminada, exemplificados pela possibilidade de dedução ilimitada de despesas com serviços ou seguros de saúde privados do imposto de renda, independentemente da classe e das quantias em questão. Estas desonerações apresentam viés regressivo, visto que privilegiam as classes mais favorecidas (com renda tributável), e mais ainda aqueles na última faixa de renda, que possuem maior capacidade de gastos ${ }^{7}$. A sobreposição entre os sistemas público e privado permite que os beneficiários da rede privada tenham acesso privilegiado a assistência médica, com possibilidade de favorecer-se dos dois esquemas, acentuando iniquidades de acesso e agravando o quadro de injustiças tributárias.

O Quadro 1 faz um resumo do perfil de cada sistema de saúde brevemente sistematizado nesta seção.

Finalmente, há que assinalar que o investimento em saúde em relação ao total da economia, bem como a participação do setor público, são profundamente distintos. Tal como indica a Tabela 1, a França apresenta gastos elevados com saúde em relação ao PIB e ao PIB per capita, com financiamento público bem acima da média mundial ( $87 \%$ de todo o gasto com saúde é público). O Brasil, por sua vez, mostra-se um caso paradoxal, com gastos em relação ao PIB equivalentes à média mundial e peso da provisão pública inferior ao gasto privado. Ademais, o gasto per capita brasileiro, estimado em 780 USD/ano, contra mais de 4,000 USD da França, corresponde a dois terços da média mundial.

Tais perfis têm rebatimentos incontroversos na posição ocupada por cada país nos rankings internacionais. Em 2000, o sistema francês foi eleito o melhor do mundo pela Organização Mundial de Saúde enquanto o Brasil foi classificado em $95^{\circ}$, numa comparação entre 191 países ${ }^{15}$. Em 2016, uma nova classificação, desta feita do Institute for Health Metrics and Evaluation, posicionou a França em $24^{\circ}$ lugar e o Brasil, em $90^{\circ 16}$.

\section{Mecanismos de financeirização da saúde}

A fim de demonstrar como a lógica da financeirização vem penetrando no campo da saúde na França e no Brasil, apontamos as transformações que reforçam a orientação comercial e financeira em detrimento de princípios solidários e redistributivos.

\section{Mudanças na natureza e comportamento dos atores da saúde}

$\mathrm{Na}$ França, o setor de seguro complementar possui um viés predominantemente solidário, com prevalência das instituições sem fins lucrativos. Em 2015, 77\% das "Organizações Complementares da Assurance Maladie" eram fundos mútuos, $4 \%$ eram institutos de previdência e somente $18 \%$ correspondiam a companhias de seguros $^{12}$. 
Quadro 1. Caracterização dos sistemas públicos de saúde da França e do Brasil - similaridades e diferenças marcantes.

\begin{tabular}{|c|c|}
\hline Institucionalidade & $\begin{array}{l}\text { Sistema de Saúde público, inserido no Sistema de Seguridade Social. Princípios de } \\
\text { universalidade na cobertura e solidariedade no financiamento. } \\
\text { França: modelo que tem origem no Seguro Social, de base contributiva e que, } \\
\text { progressivamente, amplia a cobertura e adota universalidade. Elevada descentralização } \\
\text { administrativa entre Estado e "parceiros sociais" (entidades paraestatais). } \\
\text { Brasil: origem com provisão privada e corporativa, de um lado, e filantropia para os } \\
\text { excluídos, de outro. Em 1988, Sistema Nacional de Saúde Universal significa ruptura da } \\
\text { lógica anterior (restrita e excludente), mas provisão privada segue dominante. Elevada } \\
\text { descentralização administrativa entre União, estados e municípios. }\end{array}$ \\
\hline Financiamento & $\begin{array}{l}\text { Ônus disperso pela sociedade, com diferentes bases de arrecadação. Regras de manejo e } \\
\text { controle/crescimento das despesas. } \\
\text { França: juntamente com expansão progressiva da cobertura para além do vínculo } \\
\text { contributivo original, o financiamento foi incluindo, em adição às contribuições de } \\
\text { empregados e empregadores, fontes de tributação generalizada. } \\
\text { Brasil: o acesso ao sistema público pós- } 88 \text { nunca dependeu de vínculo contributivo. O uso } \\
\text { de contribuições sociais para financiamento do sistema, apesar de constitucionalmente } \\
\text { estabelecido, nunca foi efetivado, dependendo de aplicações mínimas de receitas gerais } \\
\text { dos entes federados. }\end{array}$ \\
\hline \multirow[t]{2}{*}{$\begin{array}{l}\text { Articulação com o } \\
\text { sistema privado }\end{array}$} & $\begin{array}{l}\text { França: modelo "complementar" - setor privado complementa marginalmente a } \\
\text { cobertura da rede pública. Possibilidade de co-pagamento. }\end{array}$ \\
\hline & $\begin{array}{l}\text { Brasil: modelo "duplicado" - setor público e privado cobrem teoricamente os mesmos } \\
\text { serviços. O público é totalmente gratuito, mas sua inefetividade restringe o escopo e a } \\
\text { escala da cobertura. }\end{array}$ \\
\hline $\begin{array}{l}\text { Subsídios ao } \\
\text { sistema privado }\end{array}$ & $\begin{array}{l}\text { Desonerações sobre contribuições sociais são comuns. Porém, incentivos à aquisição de } \\
\text { seguros privados por indivíduos obedecem a lógicas diferentes. } \\
\text { França: subsídios “seletivos" (grupos específicos, para serviço complementar); } \\
\text { Brasil: subsídios "generalizados" para poucos (dedução ilimitada em termos de renda } \\
\text { individual e tipo de despesas, para serviços concorrentes) }\end{array}$ \\
\hline
\end{tabular}

Fonte: Elaboração própria, baseada na taxonomia da OECD ${ }^{11}$.

Tabela 1. Gastos com Saúde, França e Brasil (2015).

\begin{tabular}{|c|c|c|c|c|c|c|c|c|c|}
\hline & \multicolumn{3}{|c|}{ Em \% PIB } & \multicolumn{3}{|c|}{ Em US\$ per capita } & \multicolumn{2}{|c|}{$\begin{array}{c}\text { Participação } \\
\text { no Gasto } \\
\text { Total (\%) } \\
\end{array}$} & \multirow{2}{*}{$\begin{array}{l}\text { Gasto Público com } \\
\text { Saúde (\% Total Gasto } \\
\text { Público) }\end{array}$} \\
\hline & 氶 & $\frac{8}{.0}$ & 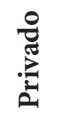 & సีㅠㄹ & $\frac{8}{\stackrel{0}{0}}$ & 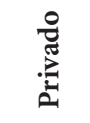 & $\frac{8}{\stackrel{0}{0}}$ & ᄅี & \\
\hline França & 11,1 & 8,7 & 2,3 & $4.026,1$ & $3.177,6$ & 848,5 & 78,9 & 21,1 & 15,3 \\
\hline Brasil & 8,9 & 3,8 & 5,1 & 780,4 & 333,6 & 441 & 42,8 & 56,5 & 7,7 \\
\hline Média mundial & 6,8 & 3,6 & & 1.012 & 658 & & 51,7 & & \\
\hline
\end{tabular}

Fonte: Organização Mundial de Saúde ${ }^{17}$. Elaboração própria. Obs: Gasto privado: somente fontes domésticas; por razões metodológicas, evitou-se o cálculo das médias mundiais ausentes neste quadro. 
As companhias de seguro dividem-se em duas subcategorias, dos quais apenas uma pode ser considerada for-profit. As companhias de seguro mútuo funcionam na lógica mutualista, embora tenham de obedecer a um conjunto de regras que se aplica ao setor financeiro; já as "sociedades anônimas", ou "seguradoras", se pautam pela busca do lucro ${ }^{12}$. Observa-se, assim, que este viés for-profit tem um papel ainda relativamente residual no caso francês, mas que avança.

Ambas as modalidades das companhias de seguro vêm disputando market-share com os fundos mútuos e de previdência, que integram a saúde complementar francesa. Em 2015, elas detiveram 29\% do total de receitas de contribuições, contra 19\% em 2001. Ainda em 2015, obtiveram um lucro líquido de 283 milhões derivados da atividade operacional de saúde, contra perdas líquidas da ordem de 9 milhões no segmento de fundos mútuos e de 153 milhões, por parte dos institutos de previdência ${ }^{12}$.

Já no Brasil, a natureza dos agentes de assistência à saúde é bem mais diversificada, pois compreende diferentes tipos de operadoras (garantindo prestação continuada de serviços e/ou cobertura de custos). Esse segmento vai desde cooperativas e instituições filantrópicas, que funcionam de alguma maneira numa lógica similar à das entidades mutualistas francesas, até as operadoras privadas que comercializam planos. O segmento for-profit, formado por seguradoras e empresas de medicina de grupo, concentra metade dos segurados (51\%) e fica com percentual equivalente do total arrecadado em prêmios (53\%), apesar de corresponder a somente um terço do número de estabelecimentos. Este segmento cresceu, a despeito de oscilações recentes, capturando 1,8 milhões de clientes entre 2011 e 2017, enquanto a carteira das entidades sem fins lucrativos (autogestão, cooperativas e filantropia) perdeu 152 mil beneficiários no mesmo período ${ }^{14}$.

Em ambos os países, além da expansão do segmento for-profit, proliferam atores teoricamente sem fins lucrativos, porém atuando em desacordo com sua vocação original, como certos fundos mútuos na França e cooperativas médicas no Brasil.

Assim, o setor de saúde parece cada vez mais dependente de atividades financeiras para seu funcionamento. Os rendimentos dessas aplicações mostram-se essenciais para compensar os baixos resultados operacionais - isto é, da atividade de provisão de saúde em si. Essas fontes de rendimentos "externas" explicam, inclusive, a expansão do mercado de saúde for-profit, mesmo sendo este ramo relativamente menos rentável do que outras atividades de seguros.

Os investimentos das entidades provedoras de seguros de saúde referem-se à utilização de receitas de contribuições e dos excedentes acumulados para a realização de aplicações que lhes permitam extrair rendimentos financeiros. Ao serem incorporados à receita total, estes rendimentos aumentam os recursos disponíveis, garantindo maior solidez financeira para fazer frente aos riscos dos segurados. Essas aplicações tomam a forma de imóveis ou de ativos financeiros, tais como ações, obrigações, empréstimos e depósitos bancários, gerando rendas na forma de aluguéis, cupons (rendimentos de títulos de renda fixa), juros e ganhos de capital (lucros sobre a venda de ativos).

A realização de investimentos pelas entidades provedoras de seguros é uma prática tradicional e regulada pelo Estado. No entanto, a dinâmica que vem assumindo recentemente levanta críticas, apontando um avanço da lógica financeira e subsumindo a proteção da saúde e os interesses dos segurados. Por um lado, identifica-se uma maior utilização de contribuições para a realização de inversões financeiras, com o peso ampliado de seus rendimentos para o resultado final das empresas - incluindo lucros milionários. Por outro, estes contrastam com menores taxas de retorno aos segurados e prêmios constantemente mais caros, atualizados acima da inflação média e dos custos do setor.

$\mathrm{Na}$ França, a maior dependência dos resultados financeiros no balanço dos organismos complementares de saúde, frente aos fracos resultados da atividade operacional, ocorre pelo menos desde 2011, recebendo destaque no relatório anual da agência regulatória do sistema financeiro: $a$ atividade de saúde, sendo levemente superavitária, e tendo resultados técnicos inferiores a $1 \%$ das contribuições, [...] constrange os organismos a compensarem este déficit técnico com produtos financeiros, a fim de manter sua rentabilidade global ${ }^{12}$.

Segundo o DREES ${ }^{12}$, três quartos dos ativos dessas instituições são investidos sob a forma de ações, obrigações, imóveis e operações de crédito. Os rendimentos financeiros derivados dos investimentos com recursos de contribuições e provisões foram essenciais para o balanço final do setor da saúde complementar. No segmento sem fins lucrativos, os produtos financeiros mais do que compensaram déficits na atividade operacional. O setor de saúde complementar obteve 24 milhões em produtos financeiros em 2015, de- 
rivados dos investimentos de receitas de prêmios, correspondendo a mais que o dobro do resultado da atividade direta de assistência ( $€ 12$ milhões).

Também no caso brasileiro, as instituições de saúde são grandes investidores institucionais e os investimentos financeiros vêm se tornando mais importantes em seu balanço. Em 2016, o setor de saúde como um todo reportou $\mathrm{R} \$ 33$ bilhões em provisões técnicas, dos quais $\mathrm{R} \$ 24$ bilhões lastreados em ativos garantidores. Segundo a ANS ${ }^{17}$, $32 \%$ dos ativos das instituições foram investidos em títulos públicos, $28 \%$ em títulos privados, $33 \%$ em "fundos dedicados" (fundos de investimentos exclusivos das operadoras junto a instituições financeiras) e $2 \%$ em imóveis.

Entre 2015 e 2016, enquanto o resultado do setor suplementar com a atividade direta de saúde caiu cerca de $\mathrm{R} \$ 800$ milhões no segmento de seguros de assistência médico-hospitalar, seu resultado financeiro aumentou em $\mathrm{R} \$ 2,8 \mathrm{bi}^{18}$. Assim, em 2016, o déficit "técnico" de R\$ 120 milhões contrasta com um superátit financeiro de $\mathrm{R} \$ 6,8$ bi. A receita com rendimentos financeiros foi maior do que o lucro final do setor ( $\mathrm{R} \$ 6,8 \mathrm{e}$ $\mathrm{R} \$ 6,2$ milhões, respectivamente). Os resultados financeiros mais expressivos foram obtidos pelas empresas de autogestão e seguradoras especializadas. Excetuando-se as cooperativas, todas as operadoras viram uma queda no resultado técnico e um aumento do resultado financeiro em relação ao ano anterior ${ }^{14,18}$.

\section{Concentração e internacionalização no setor de saúde}

Tanto o setor de "saúde complementar" francês como a "saúde suplementar" brasileira são atravessados por dinâmicas de concentração e centralização do capital. Embora a direção seja comum, as trajetórias guardam particularidades marcantes.

$\mathrm{Na}$ França, a esfera complementar passa por um intenso processo de concentração, tanto pelo lado dos grandes grupos mutualistas como pelo das seguradoras vinculadas ao setor financeiro. Entre 2001 e 2015, o número de estabelecimentos de provisão complementar reduziu-se de 1.702 para 534 , com $50 \%$ do mercado atualmente nas mãos das 20 maiores empresas ${ }^{12}$. Isto se deve principalmente à transformação constante do segmento de fundos mútuos não lucrativos, que, entre 2006 e 2016, viu seu número dividido por três. Esse processo atingiu seu ápice em 2017, com a criação grupo "VYV", fruto da união de diferentes líderes do setor mutualista. O VYV assu- miu o controle de $20 \%$ dos contratos individuais e $16 \%$ dos contratos coletivos, colocando sob sua bandeira 10 milhões de usuários e reunindo mais de 4 bilhões de Euros em fundos e reservas ${ }^{18}$.

No que concerne à internacionalização, o segmento "solidário" (fundos mútuos e institutos de previdência), ainda é majoritariamente nacional. A participação do capital estrangeiro na saúde complementar se dá principalmente através das seguradoras francesas com peso internacional e das companhias estrangeiras com forte presença no país.

No Brasil, dois processos marcantes no campo da saúde suplementar a partir dos anos 2000 foram a acelerada concentração e internacionalização das empresas de saúde, com inúmeros processos de fusões, aquisições e abertura de capital na Bolsa de Valores liderados pelo capital estrangeiro $^{7,19}$.

Desde 2007, o número de operadoras de assistência médica atuando na esfera suplementar caiu de 1.197 para $764^{14}$. Embora investidores internacionais venham ampliando sua participação na oferta de saúde pelo menos desde a década de 1970, este processo ganha fôlego novo a partir dos anos 2000. Pode-se citar, por exemplo, a aquisição do grupo nacional Amil pela norte-americana United Health em 2012, por R\$ 10 bilhões, e também a entrada do fundo americano Bain Capital no Grupo Notre Dame Intermédica em 2014 (R 2 bilhões).

Para além do ramo dos planos de saúde que integram a esfera suplementar, também o segmento hospitalar registra mudanças estruturais no que tange ao aumento do seu grau de internacionalização. Como ilustração, temos a aquisição parcial da Rede D'Or pelo banco de investimentos BTG, em 2010, por R 600 milhões, vendida, na sequência, para o fundo soberano de Singapura, em 2015, por $\mathrm{R} \$ 2,4$ bilhões.

É sabido que a internacionalização é intrinsecamente dependente do setor financeiro. Lavinas e Gentil ${ }^{7}$ identificam ao menos sete fundos de private equity que adquiriram participações em empresas nacionais de saúde (operadoras, hospitais, clínicas e laboratórios) desde 2009, muitos deles de propriedade estrangeira. As autoras ressaltam sua lógica fundamental de atuação: os fundos de private equity injetam recursos nas empresas e posteriormente vendem suas participações, normalmente com abertura do capital na Bolsa de Valores, multiplicando em muitas vezes o investimento inicial.

Bahia et al. ${ }^{19}$ revelam outra dimensão importante da internacionalização. Esta se deu, no 
caso da AMIL, pela compra de ações de empresas listadas e posterior retirada do mercado aberto. Note-se que esse processo foi consagrado em 2015, quando a lei de fundação do atual sistema de saúde brasileiro (Lei no 8.080/1990) foi alterada para autorizar a entrada de capital estrangeiro no campo da assistência médica-hospitalar (Lei $\left.n^{\circ} 13.097 / 2015\right)$ sem necessidade de autorizações especiais.

\section{Reformas e regulação do Estado}

A ação do Estado é fundamental para viabilizar transformações na direção de uma maior participação da esfera financeira no setor de saúde.

Na França, sendo os gastos com Saúde a maior parcela do "déficit" da Seguridade, justificam-se iniciativas de controle de despesas, que por sua vez favorecem atores financeiros e a expansão da provisão complementar. A partir dos anos 2000, implementam-se legislação de redução de gastos e modificação do comportamento de pacientes, tais como a criação ou a majoração de copagamentos e franquias e a imposição de condicionalidades e restrições para os reembolsos da $A M$.

De 2006 a 2011, a participação da Seguridade Social no financiamento das despesas de saúde diminuiu gradativamente, mantendo-se agora estável, principalmente por uma reorientação na natureza dos gastos: maior foco na cobertura de tratamentos e serviços de custo elevado (hospitalização, médicamentos onerosos) e nos pacientes com "doenças de longa duração" - casos que apresentam riscos financeiros e de saúde mais elevados ${ }^{20}$. O aumento dos copagamentos, das condicionalidades e das restrições de desembolso acarretam maiores "restos a pagar" para diferentes grupos de pacientes e tipos de serviços, além de estimular a demanda por seguros complementares e sobrecomplementares ${ }^{21,22}$.

A participação dos seguros complementares também foi cerceada por regras e limites, sob a justificativa de evitar comportamentos "irresponsáveis" e aumentos globais das despesas de saúde em função da redução de participação do governo. O passo central nesse sentido foi a criação da figura dos contratos "solidários e responsáveis”, também em 2004, que inibem seleção médica prévia para definir as condições do contrato de acordo com as condições de saúde do segurado (aspecto "solidário"), ao mesmo tempo em que podem reduzir os reembolsos em caso de desobediência ao "trajeto coordenado" (aspecto "responsável”). Em 2014, uma nova reforma estabeleceu tetos para determinados tipos de reembolso e reformulou a cobertura mínima obrigatória destes contratos, que atualmente correspondem a de $95 \%$ do total no país ${ }^{23}$.

As medidas de controle de despesas da $A M$ também servem de justificativa para reajustes na mensalidade dos seguros complementares em função de uma maior demanda por sua participação na cobertura de despesas, que, no entanto, encontram-se recorrentemente acima da evolução dos preços e dos custos de saúde, e da renda familiar; em 2017, por exemplo, este reajuste variou entre $2 \%$ e $5 \%$, enquanto a taxa de inflação foi de $1 \%{ }^{24,25}$.

Por fim, em 2016, ocorreu uma mudança estrutural na lógica de articulação entre o sistema público e o complementar, tornando este último obrigatório para todos os assalariados. A "generalização dos contratos complementares”, embora divulgada como uma medida positiva atendendo ao interesse geral, favorece a retração do Estado, o aumento de desigualdades de acesso aos serviços de saúde e o favorecimento do mercado de seguros privados.

A perspectiva é de generalização com precarização, pois define uma "cesta mínima de cobertura" a ser garantida por estes contratos. Como consequência, as empresas - principalmente as de menor porte, mais afetadas pela medida - tenderão a optar pela cobertura mínima obrigatória estabelecida por lei, gerando assim um "nivelamento por baixo" do setor ${ }^{23}$.

Com uma cobertura complementar mais restrita, aqueles que podem pagar são incitados a adquirir cobertura adicional com os contratos "sobrecomplementares" - estes facultativos, individualizados e restritos aos que podem pagar. A natureza destes contratos faz com que sua comercialização favoreça as grandes corporações de fundos mútuos e seguradoras privadas, que comemoram o boom do segmento, até então relativamente residual ${ }^{26}$.

No Brasil, ressaltam-se medidas que, assim como no caso francês, também permitem a segmentação de riscos no setor de saúde, estimulando o crescimento do setor privado. Neste caso, porém, o Estado subvenciona o acesso à saúde via produtos financeiros ao garantir o constante rompimento de barreiras para o acesso das camadas populares a planos e seguros, antes restritos às classes mais favorecidas e trabalhadores formais.

O grande crescimento do número de beneficiários de planos privados a partir dos anos 2000 se deu pela oferta de produtos de cobertura restrita e preço mais acessível, inclusive com o apoio 
de bancos públicos ${ }^{7,20}$, embalada pelo crescimento da renda, emprego e crédito, no contexto de "financeirização de massa" ${ }^{27}$ da economia brasileira. Além do papel do Estado subsidiando a demanda privada, sua oferta também é respaldada, uma vez que o sistema público, cobrindo os serviços negados pela primeira, garante ganhos de escala sem ameaçar sua rentabilidade? ${ }^{7}$.

Com a perda de beneficiários devido à crise econômica desde 2015, tenta-se reverter o quadro privilegiando as camadas de menor poder aquisitivo, com a reformulação da proposta dos "Planos de Saúde Populares" de 2016 (PL 7419/2006). Esta autoriza novos tipos de planos de baixo custo e cobertura altamente restrita, inferior ao mínimo atualmente exigido por lei. Também se encontra em tramitação a proposta de obrigatoriedade de empregadores garantirem planos de saúde privados a seus empregados (PEC 451/2014), em paralelo com o caso francês. Cabe, no entanto, recordar que essa medida tornaria compulsória uma prática adotada de há muito pelas grandes centrais sindicais por ocasião da negociação dos contratos coletivos de trabalho (garantia de plano de saúde privado, como salário indireto, com vantagens para as firmas que podem deduzir tais despesas do IRPJ).

O pretexto de controle de despesas incita a expansão do mercado privado, porém de forma muito mais intensa no caso brasileiro. $\mathrm{O}$ sistema de saúde nacional experimenta um processo contínuo de desfinanciamento, motor fundamental de sua deterioração, com consequente expansão da provisão privada $^{28}$. O desmantelamento da saúde pública e incentivo ao segmento privado atingiu seu ápice pela aprovação de um "Novo Regime Fiscal" (Emenda Constitucional no 95) em 2016. Congela os gastos federais por um período de vinte anos, a serem corrigidos somente pela inflação do ano anterior. A única despesa livre do "teto" é aquela destinada ao pagamento do serviço da dívida pública, remunerando os investidores financeiros. É um regime inédito no mundo, pois não considera nem mesmo fatores como crescimento do PIB ou da população.

\section{A guisa de conclusão}

Em suma, a análise comparada de França e Brasil permite observar duas dinâmicas distintas e progressivas da "financeirização" no setor de saúde.

No caso da França, o cenário de partida é um mercado complementar já plenamente estabelecido, com um forte viés solidário e provisão pública de qualidade. A privatização e a financeirização avançam através de reformas incrementais que aumentam os "restos a pagar" para diferentes serviços e grupos, estabelecem condicionalidades e limites para os reembolsos e tornam compulsória a aquisição de seguros complementares pelos assalariados.

Já no Brasil, o contexto é de um mercado ainda com grande potencial de expansão, através da conjugação entre, por um lado, o desfinanciamento e a deterioração da provisão pública, e, de outro, medidas que possibilitam sua compensação seletiva pelo segmento privado, empoderado pela abertura ao capital internacional e por um sistema generoso de isenções fiscais. Não raro, prospectos de investidores internacionais em relação ao mercado de seguros de saúde brasileiro apontam falhas do setor público e a existência de um grande mercado consumidor latente, especialmente nas camadas populares, como oportunidades de mercado. Nesse contexto, o colapso dos investimentos na saúde pública em consequência do novo regime fiscal, a legalização da entrada de atores estrangeiros na assistência e a massificação do acesso a planos de saúde privados só fazem aprofundar uma trajetória que não apenas não foi revertida com a criação do SUS, como é hoje desenhada pelo apetite insaciável da grande finança. 


\section{Colaboradores}

AC Cordilha e L Lavinas trabalharam conjuntamente nas atividades de pesquisa, metodologia, $\mathrm{e}$ redação do texto.

\section{Referências}

1. Sweezy P. The Triumph of Financial Capital. Mon Rev 1994; 46(2).

2. Epstein G, organizador. Financialization and the world economy. Cheltenham: Edward Elgar; 2005.

3. Palley T. Financialization: the economics of finance capital domination. Londres: Palgrave Macmillan; 2013.

4. Fine B. The continuing enigmas of social policy. UNRISD Working Papers; 2014

5. Bayliss K. The financialisation of health in England: lessons from the water sector. FESSUD Working Paper Series; 2016.

6. Direction de la Recherche, des Études, de L'évaluation et des Statistiques (DREES). La CSBM et son financement 2016. Paris: DREES; 2017.

7. Lavinas L, Gentil DL. Brasil Anos 2000: A Política Social Sob Regência da Financeirização. Nov Est CEBRAP No prelo 2018.

8. France. Assemblée Nationale (AN). Projet de loi de finances de la Sécurité Sociale 2018. Paris: AN; 2017.

9. Brasil. Receita Federal do Brasil (RFB). Demonstrativos dos Gastos Tributários 2016. Brasília: RFB; 2017.

10. Brasil. Secretaria do Tesouro Nacional do Brasil (STN). Aspectos Fiscais da Seguridade Social no Brasil. Brasília: STN; 2017.

11. Organização para a Cooperação e Desenvolvimento Econômico (OCDE). Proposal for a Taxonomy of Health Insurance. Paris: OCDE; 2004.

12. Direction de la Recherche, des Études, de L'évaluation et des Statistiques (DREES). La situation financière des organismes complémentaires assurant une couverture santé. Paris: DREES; 2017.

13. Direction de la Recherche, des Études, de l'Évaluation et des Statistiques (DREES). Data DREES. [acessado 2018 Jan 31]. Disponível em: http://www.data.drees. sante.gouv.fr/ReportFolders/reportFolders.aspx?IF_ ActivePath=P,344,345

14. Agência Nacional de Saúde (ANS). Dados e Indicadores do Setor [base de estatísticas]. [acessado 2018 Jan 31]. Disponível em: http://www.ans.gov.br/perfil-do-setor/ dados-e-indicadores-do-setor

15. Organização Mundial de Saúde (OMS). Relatório Mundial de Saúde. Geneva: OMS; 2000.

16. Lim S, org. Measuring the health-related Sustainable Development Goals in 188 countries. The Lancet 2015; 388.

17. Agência Nacional de Saúde (ANS). Prisma EconômicoFinanceiro da Saúde Suplementar $4^{\circ}$ trim. 2016; 2017.

18. Thevenin L. L'assurance santé française tient son nouveau géant. Les Echos 2017; Set 13.

19. Bahia L, Scheffer M, Tavares LR, Braga I. Das empresas médicas às seguradoras internacionais: mudanças no regime de acumulação e repercussões sobre o sistema de saúde no Brasil. Cad Saude Publica 2016; 32(Supl. 2):e00154015.

20. Cour des Comptes. Rapport sur l'application des lois de financement de la sécurité sociale. Paris: Cour des Comptes; 2016-2017.

21. Batifoulier P. Capital Santé: quand le patient devient client. Paris: La Découverte; 2015.

22. Abecassis P, Batifoulier P, Coutinet N, Domin JP. La généralisation de l'assurance maladie complémentaire: comment faire rimer inefficacité avec inégalité. Rev Fra de Soc-Éco 2017; 18(1). 
23. Direction de la Recherche, des Études, de l'Évaluation et des Statistiques (DREES). La complémentaire santé: acteurs, bénéficiaires, garanties. Paris: DREES; 2016.

24. Hodouin M. Tarifs des mutuelles: ce qui attend les Français en 2018. Le Furet; 2017 out 31.

25. Institut National de la Statistique et des Etudes Economiques (INSEE). Portail de statistiques. [acessado 2018 Jan 31]. Disponível em: https://www.insee.fr/fr/ statistiques

26. Perrin G. Le vrai boom des surcomplémentaires est pour 2017. Argus de l'Assurance 2016; fev 15.

27. Lavinas L, Bruno M, Araújo E. Brasil: vanguarda da financeirização entre os emergentes? Uma análise exploratória. Rio de Janeiro: Universidade Federal do Rio de Janeiro; 2017. [Texto para discussão 032].

28. Bahia L. O sistema de saúde brasileiro entre normas e fatos: universalização mitigada e estratificação subsidiada. Cien Saude Colet 2009; 14(3):753-762.

Artigo apresentado em 28/02/2018

Aprovado em 12/03/2018

Versão final apresentada em 27/04/2018 